\title{
Espaço e displacement em The Enigma of Arrival e Youth
}

\author{
Gabriel Fernandes de Miranda ${ }^{1}$ \\ Maria Conceição Monteiro ${ }^{2}$
}

\begin{abstract}
Resumo: $O$ presente artigo pretende analisar as construções de espaço em dois romances contemporâneos de língua inglesa de V.S Naipaul e J.M Coetzee a partir de uma perspectiva histórica, buscando compreender as formas de diálogo com as figurações tradicionais dos espaços narrados. Atenta-se também para o desenvolvimento de lógicas de pertencimento para os protagonistas autoficcionais dos romances, com centralidade do conceito de displacement e os mecanismos de figuração espacial que vão, paulatinamente, definindo cenários que não acolhem aos protagonistas. $\mathrm{O}$ artigo baseou-se em um referencial teórico múltiplo com especial atenção às contribuições dos estudos culturais para a compreensão do lugar da literatura no campo mais amplo de discursos que circulam na malha social. A análise se finaliza com a conclusão de que ambos os romances constroem deslocamentos radicais para seus protagonistas a partir da figuração negativa dos espaços em questão, seja aquele da Inglaterra, seja o do local de origem, produzindo uma espécie de suspensão que aponta para uma impossibilidade de pertencimento convencional para os personagens.
\end{abstract}

Palavras-chave: Displacement. Espaço. Pertencimento.

A construção de lugar na ficção se dá por uma série de mecanismos linguísticos dentro do texto, passando pela própria característica criadora da literatura. Contribuindo para a ampla gama de ficções que lidam com a condição diaspórica, as obras estudadas são efetivamente narrativas de fora que narram um mesmo espaço nacional, a Inglaterra. Ainda que haja diferença de cenários, a centralidade do campo em The Enigma of Arrival e a proeminência de Londres em Youth, as duas obras são formuladas por narradores que se identificam com os autores, de forma a deixar claro suas origens das margens do antigo Império Britânico. É através da construção dos lugares que os narradores também constroem a si mesmos e, mais importante, desconstroem uma visão apologética da grandeza da “metrópole”. Pretendo então seguir uma série de mecanismos textuais e de enredo pelos quais ambos os autores constroem e desconstroem seus cenários, levando sempre em consideração suas origens indelevelmente

${ }^{1}$ Doutorando em Literatura Comparada pela UFF. Rio de Janeiro, Brasil. E-mail: gd.miranda1@gmail.com (i) https://orcid.org/0000-0002-0789-2107

2 Doutora pela University of Nottingham (1997). Atualmente é professora titular da Universidade do Estado do Rio de Janeiro. Brasil. E-mail: mcmont@bighost.com.br https://orcid.org/0000-0002.8999-4421 
marcadas e suas negações a qualquer espaço de pertencimento "convencional", seja no bojo dos estados-nação, seja em suas línguas originárias.

É através dessa construção dos cenários que envolvem os narradores que ambas as obras acabam por solidificar um ponto de vista que se fixa no não pertencimento, no estranhamento ao meio em que eles se encontram. Assim, os narradores, nos dois casos, se constroem pelo seu modo de olhar e narrar o lugar.

A análise do espaço em textos literários merece uma breve conceptualização. O que chamarei de espaço aqui está ligado a preocupações pós-coloniais, à sua dimensão de ligação com subjetividades pelo pertencimento, familiaridade, ou os seus contrários ${ }^{3}$ (cf. BARBIERI, 2009, p. 105 apud AGUIAR, 2017, p. 138) mas também será lido com o cuidado de compreender que esses espaços ficcionais não são puras representações de espaços reais. Sua construção é cuidadosa e tem funções na narrativa para além do simples cenário, principalmente tomando funções de complementação nas construções dos personagens autobiográficos no caso dos dois romances analisados.

No presente artigo, a análise dos espaços ficcionalizados em Youth e The Enigma of Arrival passará pelo entendimento do espaço não como simples índice da realidade, como aponta Josephine McDonagh:

Lugares na literatura não são, portanto, meros marcadores que conectam textos literários ao mundo que é evocado, como um tipo de índice da realidade. Ao invés disso, a representação de lugares é parte de uma formação mais profunda do mundo que inclui nossas percepções, concepções e experiências da 'realidade' em si mesma. ${ }^{4}(\mathrm{MCDONAGH}$, 2007, p. 52. Tradução nossa)

\footnotetext{
${ }^{3}$ Claudia Barbieri (2009, p. 105 apud AGUIAR, 2017, p. 138) destaca o poder dos espaços textuais de criar "cartografias simbólicas" que unem subjetividade e história.

${ }^{4}$ No original: "Places in literature are thus not merely markers that connect the literary texts to the world that is evoked, as a sort of index of reality. Rather the representation of places is part of a more profound shaping of the world that encompasses our perceptions, conceptions, and experiences of "reality" itself" (MCDONAGH, 2007, p. 52).
} 


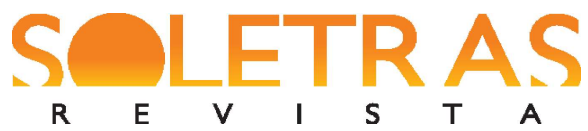

O espaço, mesmo quando ficcionalizado, faz parte ainda de uma mais ampla gama de discursos que os constroem socialmente. Ao analisar a relação dos espaços construídos nos romances de Naipaul e Coetzee, pretendo relacioná-los com tradições literárias mais amplas e, em especial, às ideias de Império e de espaço nacional construídas pela educação colonial. Dessa maneira, entendo o espaço textual também como parte de uma mais extensa "produção social do espaço" (MCDONAGH, 2007, p. 52).

Fica evidente então que os espaços textuais a serem investigados não serão tratados como mero cenário, mas sim como elementos textuais ativos na construção de subjetividade dos personagens e na reconstrução de lugares comuns do discurso, como a paisagem rural inglesa.

Primeiramente é preciso situar o corpus desse estudo. The Enigma of Arrival, de Vidiadhar Surajprasad Naipaul e Youth, de John Maxwell Coetzee, são dois romances de cunho autobiográfico surgidos em momentos diferentes, 1987 e 2002 respectivamente. Em ambas as obras os narradores possuem traços que os identificam com seus autores - em Youth a coincidência do nome do narrador John Coetzee com seu autor torna essa identificação ainda mais clara, enquanto em The Enigma, o narrador possui traços em comum com Naipaul ainda que não receba um nome - e se passam em períodos autobiográficos em que esses autores estiveram como migrantes na Inglaterra.

Apontar para o lugar originário de J.M. Coetzee e V.S. Naipaul é necessário para entender o jogo de pertencimentos e lugares assim como a dimensão de displacement colocada nesses dois livros. Os narradores autobiográficos estão fora de lugar e, mais especificamente, estão no centro do império da língua inglesa, sendo ambos indivíduos advindos das margens, de países que foram colonizados pela Inglaterra em algum momento - Coetzee vindo da África do Sul e Naipaul de Trinidad e Tobago. Portanto, é nessa condição de migrantes que os narradores se estabelecem em relação ao espaço nacional da Inglaterra. Interessam então algumas considerações sobre as questões mesmo de literaturas migrantes e os ecos da problemática pós-colonial nessas narrativas.

A categoria de displacement é fundadora para estabelecer o lugar de ambos os autoresnarradores e foi bem definida por Bill Ashcroft como um conceito de valor duplo que se refere tanto ao deslocamento físico de indivíduos no mundo, quanto a um deslocamento discursivo, no qual o sujeito se sente fora de lugar por uma supressão de sua identidade 
regional em favor do discurso imperial de "superioridade da metrópole" (ASHCROFT; GRIFFITHS; TIFFIN, 2003, p. 9). O duplo uso do displacement é uma importante ferramenta para o entendimento dos complexos efeitos discursivos de pertencimento e deslocamento produzidos em The Enigma e em Youth. Nas duas obras a característica dupla do displacement aparece presente na formação identitária dos narradores e passa, necessariamente, pela construção de espaço dos romances. Ao narrar a Inglaterra, tanto Coetzee quanto Naipaul evocam comparações com seus locais de origem e colocam sempre ambos locais em oposição e em tensão. Ainda que a Inglaterra esteja em primeiro plano, a Trinidad de Naipaul e a África do Sul de Coetzee aparecem no plano de fundo como lembranças espectrais do lar originário, contrapostas à presença na Inglaterra.

A tensão entre o local de origem e o local da migração produz uma instabilidade nos narradores, que parecem em busca de um lugar no qual seja possível pertencer. Escrevendo sobre sua própria posição de migrante indiano, Salman Rushdie sintetiza a questão da migração:

Pode ser que escritores na minha posição, exilados, ou emigrantes, ou expatriados são assombrados por um sentimento de perda, por uma urgência de recuperar, de olhar para trás [...] Mas se nós olharmos para trás devemos fazê-lo sabendo [...] que nossa alienação física da Índia significará, quase inevitavelmente, que não seremos capazes de recuperar exatamente aquilo que foi. ${ }^{5}$ (RUSHDIE, 1991, p. 10. Tradução nossa)

A pressão para o retorno ao lugar de origem a que Rushdie se refere não deixa de estar presente em Youth e The Enigma of Arrival, mas a construção dos lugares que envolvem a narrativa nos leva para além da pressão de retomar o lar de origem e indicam um outro tipo de construção de pertencimento. O importante aqui é que a construção do lugar passa por essa ficcionalização da terra natal que leva ao termo que dá nome ao livro de Rushdie, Imaginary

\footnotetext{
${ }^{5}$ No original: "It may be that writers in my position, exiles or emigrants or expatriates are haunted by some sense of loss, some urge to reclaim, to look back [...] But if we do look back we must also do so in the knowledge [...] that our physical alienation from India almost inevitably means that we will not be capable of reclaiming precisely the thing that was lost."
} 
Homelands. A ficcionalização, porém, não está somente voltada para a terra natal. Indo para além de Rushdie, é preciso afirmar que há também uma ficcionalização, uma construção textual e imaginária, do local de migração no caso de ambos os romances, da Inglaterra.

Na obra de Naipaul, o cenário da narrativa - uma casa de campo — é estabelecido desde as primeiras páginas como uma parcela do campo inglês e a função comparativa de Trinidad já é colocada em evidência:

Eu conhecia o nome da cidade na qual havia chegado de trem. Era Salisbury. Era provavelmente a primeira cidade inglesa que eu conhecera, a primeira da qual tive uma ideia [...] Lá longe na minha ilha tropical, antes de ter dez anos. Numa reprodução de quatro cores que eu achava a imagem mais bonita que eu já tinha visto. ${ }^{6}$ (NAIPAUL, 2011, p. 5. Tradução nossa)

O primeiro contato com uma ideia de Inglaterra e de Salisbury se dá no passado, em uma "moldura espacial" afastada do presente da narrativa (RONEN, 1986). A ilha tropical, seu local de origem, provoca um contraste com a paisagem de inverno de Salisbury, mas a construção da imagem do campo em um passado na colônia é bastante sintomática do efeito discursivo de displacement. As imagens da Inglaterra aparecem como as mais belas paisagens da terra, provocando um mal-estar da distância clara entre a beleza do centro e o local de origem. Como Ruth Ronen explica, as "spatio-temporally distant frames" (RONEN, 1986, p. 427) são espaços criados no texto ficcional que por vezes servem para comparação com o espaço atual da história. Em The Enigma of Arrival, a manutenção da distância de Trinidad serve, ao longo do enredo, como elemento comparativo, sempre em tensão com o local do desenrolar da narrativa central, a Inglaterra. A tensão da presença de locais tão distantes culturalmente promove também a ideia de que o narrador, alter-ego de Naipaul, não se sente pertencendo a Trinidad, e busca a tranquilidade do lar em seus arredores ingleses.

\footnotetext{
6 "I knew the name of the town I had come to by train. It was Salisbury. It was almost the first English town I had got to know, the first I had been given some idea of [...] Far away in my tropical island, before I was ten. A four-colour reproduction which I had thought the most beautiful picture I had ever seen." (NAIPAUL, 2011, p. 5)
} 
O enredo de The Enigma é permeado pela constante discrepância entre a ideia de Inglaterra e o lugar o qual o narrador experimenta (BRANNIGAN, 2003, p. 65 apud BORBOR, 2010, p. 104). É ao longo do enredo que a construção do espaço vai se modificando, assim como se modifica o ponto de vista do narrador não nomeado. Como aponta Taraneh Borbor, em um primeiro momento o narrador enxerga a Inglaterra e a seu próprio local de origem através da ideia de Inglaterra (BORBOR, 2010, p. 108) adquirida por suas leituras e da sua exposição, quando pequeno, às imagens da paisagem inglesa. A isso soma-se a descrição que o narrador faz daquela pequena região de Wiltshire onde ele se estabelece.

A solidão da caminhada, o vazio daquele trecho das colinas, permitiu renderme à minha maneira de olhar, entregar-me às minhas fantasias históricas e linguísticas; e me permitiu, ao mesmo tempo, me livrar do sentimento de ser um estranho na Inglaterra. Um acidente - a forma dos campos, talvez, o alinhamento dos caminhos e das estradas modernas, as necessidades dos militares - havia isolado essa pequena região; e eu tinha essa parte histórica da Inglaterra só para mim quando eu ia caminhar. ${ }^{7}$ (NAIPAUL, 2011, p. 18. Tradução nossa.)

A região na qual o narrador passa a habitar e a percorrer durante longas caminhadas é figurada a princípio como uma parte exemplar da Inglaterra, representante de uma sedimentação histórica única e mantida intocada pelo tempo. A imagem de um meio rural intocado pela História não é uma exclusividade de The Enigma of Arrival, e já foi analisada exemplarmente por Raymond Williams como um desenvolvimento histórico da figuração literária do meio rural inglês, com o advento, no neo-pastoral, de uma imagem do campo como um retiro, metafórico e literal (WILLIAMS, 1975, p. 23). O narrador de Naipaul, ao trazer para a sua experiência as imagens fixadas pela literatura, vê em Wiltshire o exemplo perfeito das bucólicas paisagens pastorais, nas quais o tempo não passa e onde existe uma

\footnotetext{
${ }^{7}$ No original: "The solitude of the walk, the emptiness of that stretch of the downs, enabled me to surrender to my way of looking, to indulge my linguistic or historical fantasies; and enabled me, at the same time, to shed the nerves of being a stranger in England. Accident - the shape of the fields, perhaps, the alignment of paths and modern roads, the needs of the military - had isolated this little region; and I had this historical part of England to myself when I went walking." (NAIPAUL, 2011, p. 18).
} 
constante permanência de um passado mítico, uma antiguidade indefinida: "Meu senso de antiguidade, meus sentimentos pela idade da Terra e a velhice de sua posse pelo homem, estava sempre comigo." ${ }^{\prime 8}$ (NAIPAUL, 2011, p. 19. Tradução nossa.)

Desse modo, as primeiras impressões do narrador são de uma terra bucólica e romântica, muito ligada à imagem literária que poetas como William Wordsworth e Samuel Taylor Coleridge criaram para o meio rural inglês. Em The Enigma of Arrival esse local é também construído como símbolo máximo da nação inglesa, de forma que o encontro do narrador com esse campo mítico é, também, o encontro do sujeito colonial com o mito do Império.

É somente ao desenrolar do tempo narrado que a construção do mito da "Englishness" — Inglesidade — vai se dissolvendo e o narrador passa a um outro ponto de vista, aos poucos desvelando que a glória bucólica do cenário é uma criação discursiva e imaginária descolada da sua própria experiência naquele espaço.

\begin{abstract}
Ali estava um mundo imutável [...] Assim me parecia quando eu me tornei consciente pela primeira vez da vida no campo[...] Mas essa ideia de uma vida imutável estava errada. A mudança era constante. Pessoas morriam; pessoas envelheciam; pessoas mudavam de casas [...] Esse era um tipo de mudança. Minha própria presença no vale, no chalé da casa senhorial, era um aspecto de outro tipo de mudança. ${ }^{9}$ (NAIPAUL, 2011, p. 32. Tradução nossa.)
\end{abstract}

Em um longo processo que acompanha o enredo - a vida do narrador e de sua observação da paisagem e dos personagens que povoam a propriedade de seu senhorio - o ponto de vista inicial de um local a-histórico e suspenso do tempo modifica-se para uma visão ligada à inevitável decadência de tudo e de todos, o espaço se torna então signo da imposição da passagem temporal. E a própria presença do narrador, identificado com Naipaul em sua

\footnotetext{
${ }^{8}$ No original: "My sense of antiquity, my feelings for the age of the Earth and the oldness of man's possession of it, was always with me." (NAIPAUL, 2011, p. 19).

9 "Here was an unchanged world [...] So it seemed to me when I first became aware of the country life [...] But that idea of an unchanging life was wrong. Change was constant. People died; people grew old; people changed houses [...] That was one kind of change. My own presence in the valley, in the cottage of the manor, was an aspect of another kind of change". (NAIPAUL, 2011, p. 32).
} 
dupla origem trinitina e indiana, já demonstra uma mudança radical na Inglaterra. A presença de indivíduos como o narrador só é possível a partir do ruir do Império Inglês, em um movimento diaspórico já identificado por Stuart Hall (2003), no qual a queda da influência do Império provocou uma onda de migrações no século XX. A consciência e construção textual do narrador como outsider serve à construção do espaço narrativo como um lugar onde se está eternamente des-locado, impondo uma transitoriedade àquele espaço que, ao início da narrativa, é visto como um refúgio da própria História.

É representativo o uso que Naipaul faz da caminhada no romance. É através do movimento de seu narrador que o espaço do romance se constrói, e assim o é com a própria trama do romance. Caminhando, o narrador observa e encontra os diversos personagens que compõem toda a constelação de elementos no livro. A dinâmica imposta pela mobilidade do narrador produz a própria dinâmica do romance, em especial a mudança de ponto de vista em relação ao campo, que só ocorre com a repetição das caminhadas e do ato de olhar. De modo que o caminhar se funde com o ato também de olhar, e a repetição cotidiana da caminhada leva a uma modificação da própria forma de enxergar o cenário ${ }^{10}$. Há também, evidentemente, uma imposição do cotidiano, que faz com que a paisagem deixa de ser exótica para se tornar, paulatinamente, familiarizada.

A imagem inicial da natureza se modifica também para o narrador. A paisagem observada, ao sofrer com a passagem do tempo e a ruína, passa a um estado de descontrole e o que então parecia a beleza natural do lugar se revela como obra do trabalho dos homens. Com a morte do vizinho Jack, — personagem admirado pelo narrador - o jardim, que até então parecera para o narrador uma dádiva da natureza, se torna descontrolado e perde sua forma, deixando claro o papel ordenador da atuação de Jack no lugar. Assim também, ao final do enredo, o jardineiro do senhorio, Pitton, deixa as terras, e seu legado, o jardim, também se descontrola e é atingido pelas cores irreparáveis da ruína, da morte.

Essa passagem de ponto de vista, que dá agência aos trabalhadores do campo e revela a importância do trabalho desses na formulação das paisagens controladas do meio rural, pode

${ }^{10}$ A figura de um narrador caminhante pode ser incluída em uma longa história literária de tradição europeia e dialoga, sobretudo, com o narrador Sebaldiano que viria depois. Para uma análise comparativa de Naipaul e Sebald a respeito disso cf. (MIRANDA, 2017). 
ser vista também como uma forma de subversão da imagem estereotípica criada pela literatura pastoral. Segundo Raymond Williams, é pelo apagamento dos trabalhadores que os textos neo-pastorais puderam desenvolver tons elegíacos à uma "ordem natural" que tudo dá sem esforço aos justos (WILLIAMS, 1975, p. 32), eventualmente corroborando para uma visão que elogia a natureza pura sem destacar a ação dos camponeses. A visão do narrador de Naipaul e a modificação de seu ponto de vista ao longo da estória indicam justamente um movimento oposto ao identificado por Williams. Ao dar visibilidade aos trabalhadores da propriedade de seu senhorio, desmonta-se a imagem da natureza rica e generosa e se constrói a importância da intervenção do trabalho na manutenção da beleza pastoral narrada pelos poetas do século XVIII e XIX, fazendo com que se possa corroborar a ideia de Rob Nixon de que The Enigma of Arrival poderia ser caracterizado como um "post-colonial pastoral" (NIXON, 1992, p. 102 apud BORBOR, 2010, P. 119), justamente por seu diálogo e sua negação de elementos das narrativas pastorais.

Ainda em relação a esta dimensão de ligação do romance com uma tradição literária e romântica inglesa, é possível recuperar a análise de Judith Levy (1995) em relação ao romance de Naipaul. Ao investigar de perto algumas características formais, Levy aponta para a repetição de nomes, o uso de artigos definidos e ao escasso uso de descrições minuciosas da paisagem (LEVY, 1995, p. 111). A seu ver, essa última ferramenta textual implica uma universalização do espaço narrado que nega ao leitor o acesso a uma paisagem minuciosamente detalhada: "Portanto a experiência se mantém perpetuamente como uma experiência originária para o narrador, da qual nós somos, no melhor dos casos, voyeurs." ${ }^{11}$ (LEVY, 1995, p. 111. Tradução nossa.) Pode-se acrescentar a essa análise de Levy a compreensão de que esse procedimento acaba produzindo uma fantasmagoria do local, uma estranha névoa que torna essa uma paisagem indiferenciada, dificultando a criação de imagens mentais no processo de leitura. O que essa espectralidade implica é também a ficcionalidade de todos os espaços — e, em especial, dos espaços figurados no texto - , ou seja, ao narrar de forma incompleta os seus arredores, Naipaul produz uma paisagem que aponta para o seu próprio processo de invenção e seu caráter, portanto, incompleto. $\mathrm{O}$ romance não apresenta

\footnotetext{
${ }^{11}$ No original: "Thus the experience remains perpetually an originating experience for the narrator, one of which we are, at best, voyeurs." (NAIPAUL, 2011, p. 111).
} 
descrições detalhadas típicas do realismo romanesco justamente para indicar o processo imaginativo da escrita de locais, em uma jogada auto-reflexiva utilizada ao entorno de problemas pós-coloniais $^{12}$, como aponta também Judith Levy (1995, p. 121).

O procedimento de Naipaul em relação ao espaço é bastante transparente. Ainda que o romance seja marcado também por uma desconstrução da linearidade do tempo, em relação principalmente aos capítulos, que não possuem uma ligação cronológica clara entre $\mathrm{si}^{13}$ (LEVY, 1995, p. 107), no desenrolar da própria narrativa a virada de perspectiva do personagem autobiográfico é que dá o tom dos espaços narrados. Ao espaço inglês vai sendo deposta a característica a-histórica e em seu lugar se firma uma transitoriedade — iniciada principalmente pela inclusão de imagens da morte e da ruína no romance — de forma que aquele fragmento espacial passa a ser incluído no tempo. A inclusão de um ritmo no meio rural inglês é então uma desmitificação desse espaço ${ }^{14}$ (MIRANDA, 2017), na medida em que o local temporalizado é local experimentado, frustrando então a dimensão imaginativa e discursiva que o narrador impunha à Inglaterra como um todo. Através do tempo, o espaço perde sua dimensão mítica.

Apesar de sempre demarcar sua posição de outsider, o narrador de The Enigma of Arrival produz uma visão da Inglaterra que dialoga profundamente com a tradição literária daquele país, em uma estratégia de Naipaul para se introduzir em um certo cânone de língua inglesa (BORBOR, 2010, p. 120). Contudo, ao demarcar sua diferença cultural e sua origem outra, a construção do espaço no em The Enigma of Arrival acaba subvertendo formas comuns de narrar o campo inglês, impondo uma re-escritura daquele local que é, de certa maneira, uma sinédoque para a própria construção discursiva de uma nacionalidade Inglesa. Portanto, o próprio ato de re-escrever esse espaço da Englishness ${ }^{15}$ (BORBOR, 2010, p. 108) é

${ }^{12}$ Aqui também ecoo as ideias de Levy de que Naipaul mistura repertórios dos campos pós-moderno e póscolonial.

${ }^{13}$ Judith Levy identifica no romance uma tendência a um procedimento de aproximação de personagens e fatos ocorridos no tempo. Para ela, o primeiro capítulo, Jack's Garden possui a totalidade do tempo passado em Wiltshire enquanto os outros capítulos seriam como recortes menores e não lineares de acontecimentos dentro dessa totalidade temporal.

${ }^{14}$ Como argumentamos em outro texto, The Enigma of Arrival performa um processo de desestabilização e reconstrução de uma imagem estabilizada do meio-rural inglês, produzindo ao contrário, uma imagem contraposta às ideias de glória e beleza imperiais (MIRANDA, 2017).

${ }^{15}$ É Taraneh Borbor que aponta a ligação do narrador de The Enigma of Arrival com o mito discursivo dessa "inglesidade" herdada justamente da tradição literária inglesa. 
uma possibilidade da alçada das literaturas advindas das margens dos antigos impérios coloniais para uma posição central.

Em Youth, de J. M. Coetzee, há pontos em comum com essa construção de lugar mediada por um ponto de vista da superioridade da metrópole presente em The Enigma of Arrival. O protagonista do romance narrado em terceira pessoa, e que é também um alter-ego do autor, John Coetzee, passa por uma mudança de ares durante a narrativa. Se em The Enigma of Arrival o narrador passa todo o tempo na Inglaterra, evocando o seu local de origem apenas como moldura comparativa, em Youth, o jovem John Coetzee é introduzido como um estudante de matemática vivendo uma vida medíocre em Cape Town, na África do Sul, ainda no local à margem da metrópole.

Modulada por um deslocamento textual que torna a vida pacata e pelo distanciamento provocado pelo uso da terceira pessoa (LENTA, 2003, p. 158) a narrativa de Coetzee se utiliza muitas vezes de tons irônicos e depreciativos para com o jovem protagonista John Coetzee. O tom de desprezo adotado pelo e para o protagonista - já que o romance se utiliza quase em sua inteireza do mecanismo do discurso indireto livre, a voz do personagem é quase sempre evocada sem indicação direta — se estende, é claro, para os locais em que ele se situa. A sua impressão da África do Sul é explicitada em um trecho em que John e seu amigo Paul compram leite de um leiteiro negro, levando a uma observação consciente da divisão racial e que deprecia o espaço sul-africano em que se encontra: "Mais profundo do que pena, mais que acordos honráveis, mais profundo até do que caridade, se encontra uma compreensão de que pessoas como Paul e ele mesmo [...] estão nessa terra pelos pretextos mais instáveis." "16 (COETZEE, 2003, p. 17. Tradução nossa). E finaliza com a afirmação que demonstra a herança desses jovens brancos: "[...] o chão debaixo dos seus pés está encharcado de sangue e a vasta profundidade da história ecoa com gritos de raiva."17 (COETZEE, 2003, p. 17. Tradução nossa).

A descrição desse espaço sul-africano como um lugar necessariamente injetado com o passado e o presente de exclusão racial e imposição dos brancos sobre a população nativa

\footnotetext{
${ }^{16}$ No original: "Deeper than pity, deeper than honourable dealings, deeper even than goodwill, lies an awareness on both sides that people like Paul and himself [...] are here on this Earth of South Africa on the shakiest of pretexts" (COETZEE, 2003, p. 17).

${ }^{17}$ No original: "[...] the ground beneath his feet is soaked with blood and the vast backward depth of history rings with shouts of anger."
} 
negra já indica também um displacement do personagem em relação a essa herança. Ao notar esse passado imposto à terra, o protagonista se distancia da própria origem e percebe a instável permanência dos brancos na África do Sul e sua condição irrevogável de estrangeiros. Esse estrangeirismo em seu próprio lar é elemento constitutivo do personagem autobiográfico de Coetzee. De fato, a insistência no atraso da África do Sul e na violência causada pelos brancos naquele país são utilizados, no avançar do enredo, como argumento na trama que levam o jovem Coetzee a migrar para Inglaterra.

Aqui cabe um pequeno parêntese para investigar um ponto chave nessas duas ficções. Nos dois livros, a migração para a Inglaterra é feita por ímpeto próprio dos personagens. Suas ambições literárias e culturais pesam em suas imagens da Inglaterra como centro de cultura e avanço. O que isso implica é justamente a necessidade de insistir no caráter individual, opondo-se a uma experiência coletiva de diáspora, dessas experiências de displacement. Um deslocamento voluntário é distinto de uma migração forçada por guerras ou condições econômicas, portanto, resta notar que nestes dois romances a dimensão de diáspora não se entende como experiência coletiva. Antes, essas ficções devem ser lidas como tentativas na dimensão subjetiva de se lidar com a migração. Dito isso, com a leitura de Youth e The Enigma, fica evidente que apesar de experiências privilegiadas, a subjetividade migrante é figurada textualmente a partir de uma negatividade, com uma caracterização de nãopertencimento, presente nas experiências da diáspora em geral.

Voltando ao romance de Coetzee tem-se que, ao mesmo tempo em que a África do Sul é construída textualmente como um espaço do unhomely (BHABHA, 2014, p. 31), a metrópole, ou seja, a Inglaterra, aparece nos trechos iniciais do livro como uma moldura espacial distante e que imputa a personagens que já estiveram lá um certo status como a enfermeira Jacqueline, com quem o jovem Coetzee tem um caso amoroso:

Jacqueline, no entanto, não é uma enfermeira ordinária. Ela é [...] treinada em obstetrícia no Hospital Guy em Londres [...] Ela trabalha não no Groote 
Schuur, o hospital público, mas sim em um asilo privado, onde o pagamento é melhor. ${ }^{18}$ (COETZEE, 2003, p. 6. Tradução nossa)

Londres se apresenta então como local de distinção social e como centro de formação, prefigurando o destino do protagonista em sua jornada até a Inglaterra. A narrativa aos poucos justifica a mudança de ares de John Coetzee ao tensionar o local de origem e a metrópole em toda a sua possibilidade de alçar o jovem a uma melhor posição social. A promessa implica uma certa imagem de Londres - e da Inglaterra - que depois será confrontada na própria experiência do protagonista.

Também em Youth a relação entre o protagonista e a literatura é bastante forte e é através da leitura e da expectativa literária que ocorre seu encontro com o mundo. A narrativa em estilo indireto livre quase ininterrupto nos mostra por vezes a voz do protagonista em suas opiniões e desejos: "A ambição dele é ler tudo que vale a pena ler antes de ir para além-mar, para que ele não chegue na Europa como um caipira provinciano."19 (COETZEE, 2003, p. 25. Tradução nossa). A visão de si mesmo como um provinciano indica também o lugar que o espaço europeu ocupa nas referências culturais do jovem Coetzee. Essa centralidade da cultura europeia e a depreciação da sua própria cultura e status "provincianos" são frutos daquele mesmo displacement discursivo que também se apresenta em The Enigma of Arrival.

Fixando a Inglaterra como local imbuído de civilização e cultura em oposição à sua África do Sul sem tradição e manchada de sangue, o romance de Coetzee promove dois efeitos. Primeiro, o deslocamento discursivo que produz o domínio imperial, que relega os países do "terceiro mundo" a uma posição subalterna e à margem, imputando aos sujeitos desses locais um sentimento profundo de inferioridade. Segundo, através desse primeiro deslocamento da subjetividade do jovem Coetzee, o romance empurra conscientemente esse personagem para um espaço de não-pertencimento, de maneira que o jovem alter-ego é

\footnotetext{
${ }^{18}$ No original: “Jacqueline, however, is no ordinary nurse. She is (...) trained in midwifery at Guy's Hospital in London (...) She works not at Groote Schuur, the public hospital, but at a private nursing home, where the pay is better." (COETZEE, 2003, p. 6).

${ }^{19}$ No original: "His ambition is to read everything worth reading before he goes overseas, so that he will not arrive in Europe a provincial bumpkin." (COETZEE, 2003, p. 25).
} 
construído como um sujeito fora do lugar abrindo caminho para a insistência em uma subjetividade sem pertencimento possível.

Até na chegada de Coetzee em Londres há uma permanência desse tipo de imagem da cidade como centro cultural do ocidente, no qual a capital inglesa funciona em Coetzee como o pequeno pedaço de terras em Wiltshire funciona em Naipaul. Ambos se estruturam e são construídos como espaços-signos da civilização ocidental, ambos ligados a uma ampla tradição literária e canônica. Apesar das diferenças evidentes entre a descrição sublime de Naipaul do meio rural e a pacata narrativa irônica de Coetzee de Londres, ambos os espaços ficcionais servem inicialmente a essa mesma função. Imbuídos de significação cultural, são estereótipos literários trazidos para a experiência, provocando um choque que promove um processo de virada de ponto de vista em ambos os romances.

Ainda na África do Sul, a saída de John Coetzee do país é precipitada e justificada pelos conflitos raciais que escalam em seus últimos anos de estudante de matemática na universidade. Uma dupla ameaça parece causar uma “expulsão’ de John Coetzee de sua terra natal: a presença de grupos de ativismo negro que pedem a expulsão dos brancos de suas terras originárias e a ameaça da convocação para o serviço nas tropas militares do apartheid (COETZEE, 2003, p. 39). Essa estratégia ficcional-memorialística transforma a saída do jovem John Coetzee - ao mesmo tempo uma figuração de um eu passado do próprio autor e uma ficcionalização desse mesmo jovem - em uma escolha necessária, como uma resposta à dupla ameaça. Mas dentro do próprio texto os propósitos do jovem Coetzee já haviam sido explicitados: "Seu plano, quando ele entrou na universidade, era se qualificar como um matemático e, então, ir para fora e se devotar à arte." ${ }^{20}$ (COETZEE, 2003, p.22. Tradução nossa). Apesar da justificativa dos conflitos raciais, a migração do protagonista tem bases na expectativa do protagonista de se tornar um artista e de usufruir do espaço cultural europeu e, mais especificamente, inglês, para isso. A oposição entre uma justificativa nobre para a saída — as injustiças do regime sul-africano — e a expectativa artística ridicularizada por todos complica o jogo entre referencialidade e ficção, colocando uma dupla névoa, construída na ficção, sobre a própria saída de J. M. Coetzee, o autor, de sua terra natal.

\footnotetext{
${ }^{20}$ No original: "His plan, when he entered the university, was to qualify as a mathematician, then go abroad and devote himself to art." (COETZEE, 2003, p. 22).
} 
Assim como em The Enigma of Arrival, o processo de decepção com o novo lugar se inicia rapidamente. Já na chegada de Coetzee à Londres, ele nos indica que a cidade em que ele se encontra é na verdade a última opção em uma gama de cidades onde seria possível cultivar seu espírito artístico:

Existem dois, talvez três, lugares no mundo aonde a vida pode ser vivida na sua máxima intensidade: Londres, Paris, e talvez Viena. Paris vem primeiro: cidade do amor, cidade da arte. [...] Já Viena, Viena é para os judeus retornando para reclamar seus direitos de nascença [...] Sobra Londres, aonde Africanos do Sul não precisam de vistos e aonde as pessoas falam inglês. ${ }^{21}$ (COETZEE, 2003, p. 41. Tradução nossa).

A escolha por Londres é, portanto, textualmente caracterizada por um pragmatismo que contrasta com a visão romântica de John acerca de Paris. Mesmo na chegada, Londres não é exatamente o que se espera, ela não é Paris, não é o centro real das artes ocidentais na visão do protagonista, mas sim uma cidade na qual é mais fácil sobreviver pelas proximidades culturais entre Inglaterra e África do Sul. E essa proximidade se materializa logo em seguida, quando John consegue um emprego na IBM e rapidamente se torna irreconhecível na multidão londrina. Seu terno preto e sua pele branca o fazem rapidamente um cidadão comum em território estrangeiro, mas em seu interior sua condição de outsider é insistentemente marcada no texto.

A partir de sua chegada, lentamente Londres, que antes se figurava como horizonte de cultura e distinção social na África do Sul, se torna quase insuportável. A cidade simbiotiza-se com os sentimentos negativos do próprio personagem: "Então a solidão que ele geralmente consegue espantar varre sobre ele, solidão indistinguível do clima baixo, cinza e úmido de

\footnotetext{
${ }^{21}$ No original: "There are two, perhaps three places in the world where life can be lived at its fullest intensity: London, Paris, perhaps Vienna. Paris comes first: city of love, city of art. [...] As for Vienna, Vienna is for Jews coming back to reclaim their birthright [...] That leaves London, where South Africans do not need to carry papers and where people speak English." (COETZEE, 2003, p. 41).
} 
Londres ou do frio duro como ferro do asfalto." 22 (COETZEE, 2003, p. 52. Tradução nossa). Essa caracterização de lugar indica uma cidade e, consequentemente, um espaço nacional que não é acolhedor, mas sim o seu contrário, opressivo. Ao aceitar o posto em um trabalho comum de escritório e apesar de começar seus estudos sobre Ford Madox Ford para um mestrado em literatura, o jovem Coetzee tem sua vida esvaziada, e toda a expectativa que estava imbuída na saída de Cape Town para a Europa se prova falha e irreal. Longe dos meios artísticos, o personagem autobiográfico de J. M. Coetzee vaga solitário e decepcionado pelas ruas de uma capital escura e chuvosa.

Como o título do romance explicita, toda a construção narrativa do personagem de John está eminentemente ligada à sua condição de juventude. Seu desespero, sua dificuldade de se relacionar com a família e consigo mesmo são também características desse momento da vida figurado no romance. E é a partir da ótica da juventude, desse momento indefinido de amadurecimento que o romance constrói os espaços pelos quais passa o jovem John, transpondo assim as instabilidades típicas da juventude ao espaço narrado.

A construção dos espaços em Youth não é tão convencional e descritiva como acontece em The Enigma of Arrival. São poucos os trechos nos quais o narrador caracteriza detalhadamente os espaços por onde a protagonista passa. Ainda que haja essa dificuldade, a construção de espaços ficcionais não precisa se dar diretamente pelo texto, mas, como aponta Ruth Ronen, as ações que se constroem textualmente estão situadas em espaços ficcionais, e essas ações, as trocas e os movimentos de personagens são também formadores dos cenários da trama ficcional (RONEN, 1986, p. 432). A própria escolha narrativa de Coetzee por uma prosa carregada do estilo indireto livre coloca como elemento central do enredo o próprio desenvolvimento interior do personagem principal e seus pensamentos, significando que a construção dos cenários acontece indiretamente dependendo do desenrolar dos fluxos de consciência de John Coetzee.

Torna-se essencial então notar que o romance de Coetzee trata de uma formação frustrada, na qual a mudança da província para a metrópole não acarreta em uma explosão

\footnotetext{
${ }^{22}$ No original: "Then the loneliness that he usually manages to keep at bay sweeps over him, loneliness indistinguishable from the low, grey, wet weather of London or from the iron-hard cold of the pavements." (COETZEE, 2003, p. 52).
} 
artística e inspiracional no jovem com aspirações para o fazer literário. Pelo contrário, ao fim do desenrolar do enredo, após três anos na Inglaterra, o jovem Coetzee se vê justamente abandonando a poesia e cada vez mais voltado para a matemática.

De fato, considero de especial importância para a investigação do romance a ideia de Bildungsroman, ou romance de formação. Esse conceito, espécie de "lugar comum" da crítica literária (Cf. OLIVEIRA, 2013), apesar de sua indefinição e uso desregrado, parece ser importante na medida em que é contraposto por Youth. O Bildungsroman, com origem comumente identificada no romance de Goethe Os anos de aprendizado de Wilhelm Meister, em sua definição mínima, tende a se ligar ao desenvolvimento individual até um ápice de completa absorção de qualidades humanas positivas pelo personagem (SELBMANN, 1988, p. 121 apud OLIVEIRA, 2013). Ainda que o uso indiscriminado desse conceito seja criticável, sua cristalização na teoria e crítica literárias é inegável, de modo que o uso do distanciamento da terceira pessoa e o tom irônico do romance de Coetzee podem ser lidos como formas de estabelecer um diálogo intertextual que se contrapõe a esse lugar comum do romance de formação, tal como Naipaul o faz em relação à tradição pastoral e romântica de figuração do campo.

O tratamento irônico de J. M. Coetzee desses anos de formação de si mesmo nos leva também a um final que está longe do equilíbrio indivíduo/mundo identificado por Lukács (2009 [1920], p. 138) na obra marcante de Goethe. Em Youth o enredo não leva a uma solução da problemática distância entre o jovem Coetzee e o mundo. Ao contrário, não resolvido esse conflito, o romance se coloca em oposição dialógica às expectativas de um romance de formação de um jovem. Consciente da permanência do romance de formação como ótica de leitura comum, ainda que imperfeita, mais uma vez, J. M. Coetzee joga uma pá de cal sobre as expectativas do leitor.

A Bildung contrariada de Youth serve-nos, na dimensão espacial do romance, para indicar justamente a quebra das expectativas imputadas na Londres ficcional. $\mathrm{O}$ espaço que seria propício para o desenvolvimento do personagem é construído, ao contrário, como um lugar de normatização e de arrefecimento das potências artísticas de John. Como manifestação dessa insatisfação, em um trecho na metade do livro, o narrador, tomando a voz de John, nos diz: "Ele não dominou Londres. Se há alguma dominação acontecendo, é Londres 
dominando-o". 23 (COETZEE, 2003, p. 63. Tradução nossa). Essa afirmativa, logo depois da revelação de que o jovem Coetzee passou a escrever prosa com cenários na África do Sul, indica a impossibilidade de pertencer e comandar a Inglaterra, inserindo no personagem também uma impossibilidade de escrevê-la.

Quase no mesmo momento da narrativa, o jovem Coetzee passa a "retornar" imaginariamente para a África do Sul nas ficções que escreve. Mais à frente, cansado de sua tese, ele se volta para a leitura de memoriais de pioneiros sul-africanos (COETZEE, 2003, p. 137). Dessa maneira, concomitante à sua definitiva decepção com a Inglaterra, o personagem autobiográfico é levado de volta à Imaginary Homeland de que fala Salman Rushdie. O retorno imaginado - apesar de não escolhido — aparece também em Youth como destino inescapável do sujeito migrante. A impossibilidade de escrever a Inglaterra e a capacidade única do jovem Coetzee de se voltar para a África do Sul tanto em suas leituras quanto em sua escrita é como um sintoma da condição que David Atwell identificou em toda a obra de Coetzee: "Todavia, eu sugiro que para Coetzee como assunto/agente da escrita, de uma vidade-escrita, o fato da África do Sul como o milieu não escolhido, mas intimamente conhecido, não pode ser sobre enfatizado". ${ }^{24}$ (ATWELL, 2008, p. 237. Tradução nossa).

A África do Sul aparece ao longo de Youth como um lugar opressivo, provinciano, e absolutamente hostil ao jovem Coetzee e sua vontade artística. Ainda assim, esse local de origem parece voltar como uma assombração, à revelia da vontade de John em uma estranha dinâmica que não permite jamais a volta completa a essa homeland, ao mesmo tempo em que o completo abandono desse passado não lhe é permitido. A figuração do lugar de origem como um assombro e uma presença que parece emergir na vida dos personagens autobiográficos está presente em Youth como em The Enigma of Arrival.

Através da narração, mostra-se a aflição do personagem com sua própria fascinação com seu local de origem:

\footnotetext{
${ }^{23}$ No original: "He has not mastered London. If there is any mastering going on, it is London mastering him." (COETZEE, 2003, p. 63).

${ }^{24}$ No original: "Nevertheless, I suggest that for Coetzee as the subject/agent of writing, of a life-of-writing, the fact of South Africa as the unchosen but intimately known milieu cannot be over-emphasized." (ATWELL, 41, 2008, p. 237).
} 
Patriotismo: é isso que está começando a afetá-lo? Ele está se provando incapaz de viver sem um país? Tendo chacoalhado a poeira da feia e nova África do Sul de seus pés, ele agora está ansiando pela África do Sul dos velhos dias, quando o Éden ainda era possível? ${ }^{25}$ (COETZEE, 2003, p. 137. Tradução nossa)

Caberia responder ao jovem personagem que se trata de um efeito conhecido do deslocamento de sujeitos essa vontade de retorno, que só pode se dar na ordem simbólica, na medida em que não há, realmente, locais de origem fixos.

A construção de um cenário citadino no romance de Coetzee certamente contrasta com as paisagens rurais de Naipaul. Ambos, porém, estão certamente escrevendo através de imagens estereotípicas desses dois ambientes. Como indica Raymond Williams, o contraste entre cidade e campo é um tópos bastante antigo em toda a literatura, cuja sedimentação de significados tendeu a estabilizar o campo como local da natureza e paz enquanto à cidade tendeu a se unir uma ideia de aprendizado e comunicação (WILLIAMS, 1975, p. 1). Essas imagens tradicionais são justamente aquelas às quais subscrevem os dois alter-egos de Naipaul e Coetzee inicialmente, apesar de, aos poucos, essas imagens serem desconstruídas - especialmente o caráter a-histórico e pacífico do campo em The Enigma of Arrival. Em Youth, porém, parece haver uma inversão de ponto de vista, a construção de Londres como centro artístico e de aprendizado é rapidamente trocada por uma visão negativa - que Raymond Williams também apontou como recorrente — de um espaço mundano e pueril. E, corroborando com a oposição convencional entre mundo natural e espaço urbano, o jovem Coetzee chega a um momento de simples e inesperada paz no parque de Hampstead Heath:

Ele costumava ser impaciente com poemas sobre flores em botão e brisas zefirosas. Agora, na terra em que esses poemas foram escritos ele começa a

\footnotetext{
${ }^{25}$ No original: "Patriotism: is that what is beginning to afflict him? Is he proving himself unable to live without a country? Having shaken the dust of the ugly new South Africa from his feet, is he yearning for the South Africa of the old days, when Eden was still possible?" (COETZEE, 2003, p. 137).
} 
entender o quão profunda a felicidade pode correr com o retorno do sol. ${ }^{26}$ (COETZEE, 2003, p. 117. Tradução nossa)

Também nessa passagem o conhecimento literário intervém. Contudo, ele o faz de uma maneira oposta àquela que se coloca em The Enigma of Arrival e mesmo no início de Youth. A experiência do personagem se opõe à suas impressões literárias dando um cunho positivo a uma imagem literária que o jovem Coetzee havia desprezado, a de um mundo natural belo e pacífico. Diante do ambiente sufocante da cidade, a "paisagem natural" (note-se a dimensão construída de toda paisagem e especialmente de parques como esse, cuja construção é baseada em uma ideia particular de natureza) aparece como um refúgio, tal como ela é caracterizada na literatura neo-pastoral. O trecho finaliza com uma conclusão que indica o equívoco das expectativas do personagem quanto a Londres e um elogio a esse momento fugidio de refúgio natural:

Ele fez a jornada até a cidade grande e escura para ser testado e transformado, e aqui, nesse retalho verde sob o sol fraco de primavera seu progresso veio, surpreendentemente. Se ele não foi completamente transfigurado, então ao menos ele foi abençoado com uma pista de que ele pertence a este mundo. ${ }^{27}$ (COETZEE, 2003, p. 117. Tradução nossa)

É no espaço da "natureza" ficcionalizada do parque que o jovem Coetzee finalmente encontra uma "literariedade" (cf. ENGLE, 2009) no mundo, ou seja, há um encontro entre sua sensibilidade artística e a experiência. É o momento no qual as ambições literárias do protagonista e suas leituras se fundem com a experiência, contrastando com a relação anteriormente figurada no romance de oposição entre arte e vida. O mais notável é que esse tipo de encontro só ocorre ali, naquele único espaço ficcional e unicamente neste trecho. Esse

\footnotetext{
${ }^{26}$ No original: "He used to be impatient of poems about budding flowers and zephyrous breezes. Now, in the land where those poems were written, he begins to understand how deep gladness can run at the return of the sun." (COETZEE, 2003, p. 117).

${ }^{27}$ No original: "He journeyed to the great dark city to be tested and transformed, and here, on this patch of green under the mild spring sun, word of his progress has, surprisingly, come. If he has not utterly been transfigured, then at least he has been blessed with a hint that he belongs on this earth." (COETZEE, 2003, p. 117).
} 
momento de sentimento sublime se figura na completude do texto tal como aparece na vida do jovem Coetzee, apenas um momento fugidio, impossível de se repetir. Também é ali nesse tempo e nesse espaço que ele parece se sentir em uma relação de pertencimento com algum lugar. Se a África do Sul e Londres se constroem no texto como locais de não-pertencimento por excelência, é ali naquele pedaço verde que os mecanismos de des-locamento textuais são esquecidos e ao jovem Coetzee é permitido um momento de tranquilidade.

A presença desse momento de equilíbrio entre expectativa/experiência e entre indivíduo/mundo é bastante significativa. Não por que resolve ou termina o romance, mas sim por sua condição passageira. A realidade é que o romance não constrói esse momento como um sopro final de esperança. De fato, apesar desse pequeno momento que corrobora com certos estereótipos de localizações ficcionais, o tom do romance continua se aproximando da decepção com o espaço migratório, sem que o conflito do protagonista com seu meio se resolva.

Mesmo após se mudar para uma vila no interior da Inglaterra em um novo posto de trabalho para a IBM, o jovem Coetzee se vê no centro ainda de um processo contrário às suas expectativas. Ele abandona a leitura e a escrita de poemas, ainda que também abandone o terno preto e a cidade cinzenta de Londres. A mudança para a Europa, que deveria impulsionar suas criações artísticas, acaba em três anos, transformando-o cada vez mais em um matemático e em um bom funcionário de uma grande empresa. Mesmo a mudança de ares de Londres para o campo não modifica a sua sina de abandono da arte e o processo de deterioração de si próprio se eleva no fim do romance:

Aos dezoito ele poderia ter sido um poeta. Agora ele não é um poeta, nem um escritor, nem um artista. Ele é um programador de computadores, um programador de computadores de vinte e quatro anos em um mundo em que não há programadores de trinta anos. Aos trinta se é velho demais para ser um programador: torna-se outra coisa - um tipo de homem de negócios ou atira-se em si mesmo. ${ }^{28}$ (COETZEE, 2003, p. 168. Tradução nossa).

\footnotetext{
${ }^{28}$ No original: "At eighteen he might have been a poet. Now he is not a poet, not a writer, not an artist. He is a computer programmer, a twenty-four-year-old computer programmer in a world which there are no thirtyyear-old computer programmers. At thirty one is too old to be a programmer: one turns oneself into something else - some kind of businessman - or one shoots oneself." (COETZEE, 2003, p. 168).
} 
É com esse tom sinistro que se encerra a narrativa. O enredo, através da construção de lugares, transforma um jovem com ambições artísticas em mais um empregado de uma multinacional, ceifado de toda expectativa para o futuro. Ao longo de Youth, então, o jovem Coetzee se vê perdido na Inglaterra às voltas com a eterna assombração que lhe provoca a sua origem provinciana, sul-africana, e a impossibilidade de se sentir acolhido no espaço nacional para onde ele havia migrado, seja no centro metropolitano, como na bucólica paisagem do interior.

Assim como em The Enigma of Arrival, a construção dos espaços migratórios ficcionais passa por uma construção prévia baseada em experiências de leitura dos sujeitospersonagens autobiográficos. Ao reescreverem a si mesmos e a suas experiências como migrantes das colônias na metrópole, tanto Naipaul como Coetzee utilizam uma série de recursos textuais que ajudam a reconstruir os seus próprios displacements. Em ambos, o processo de decepção com a imagem da metrópole herdada de uma educação colonial leva também à impossibilidade de pertencer ao espaço cultural da Inglaterra. Essa terra estrangeira parece sempre negar o completo pertencimento a esses sujeitos que são, fundamentalmente, de fora. Ao mesmo tempo, está presente tanto em Youth como em The Enigma of Arrival a impossibilidade de reaver a terra natal. Tal como Salman Rushdie havia indicado, para o sujeito migrante a recuperação da terra natal só pode se dar a partir de ficcionalizações desse espaço originário.

\section{Referências}

AGUIAR, Cristhiano. Narrativas e espaços ficcionais: uma introdução. São Paulo: Editora Mackenzie, 2017.

ASHCROFT, Bill; GRIFFITHS, Gareth; TIFFIN, Helen. The empire writes back: Theory and practice in post-colonial literatures. New York: Routledge, 2003.

ATWELL, David. Coetzee's Estrangements. Novel: A forum of fiction, 2008, v. 41, n. 2/3. p. 229-243.

BARBIERI, Claudia. “Arquitetura literária: sobre a composição do espaço narrativo.”. In: BORGES FILHO, O.; BARBOSA, S. (Orgs.). Poéticas do espaço literário. São Carlos, Claraluz, 2009.

BHABHA, Homi. O Local da Cultura. 2a ed. Belo Horizonte: Editora UFMG, 2014 


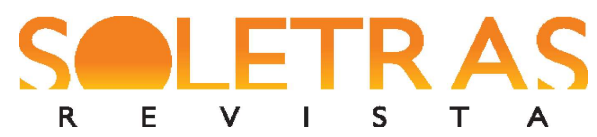

N. 38 - 2019.2 - GABRIEL FERNANDES DE MIRANDA

MARIA CONCEIÇÃO MONTEIRO

BORBOR, Taraneh. Towards a New Geographical Consciousness: A Study of Place in the Novels of V.S. Naipaul and J.M. Coetzee. 2010. 291 f. Tese (Doutorado em Literatura Inglesa). The University of Sussex, Brighton, 2010.

BRANNIGAN, John. "In pursuit of English": Postcolonial writers in England, 1945-1965" New Literatures Review, 2003, n. 39, p.61-74.

COETZEE, J.M. Youth. Londres: Penguin Books, 2003.

ENGLE, Lars. Being literary in the wrong way, time, and place: J.M Coetzee's Youth. English Studies in Africa. N ${ }^{o}$ 49, v. 2. p. 29-49. Tulsa, Oklahoma, 2009. Disponível em: $<$ http://dx.doi.org/10.1080/00138390608691353>.

HALL, Stuart. Pensando a Diáspora In. Da Diáspora: Identidades e Mediações Culturais. Belo Horizonte: Editora UFMG, 2003.

LENTA, Margaret. Autrebiography: JM Coetzee's "Boyhood and Youth". English in Africa, 2003, v. 30, n. 1, p. 157-169.

LEVY, Judith. V.S. Naipaul: displacement and autobiography. New York: Garland Publishing, 1995.

LUKÁCS, Georg. Os anos de aprendizado de Wilhelm Meister como tentativa de uma síntese. In. . A Teoria do Romance. Trad. José Marcos Mariani de Macedo. 2. ed. São Paulo: Duas Cidades; Editora 34, 2009 [1920].

MCDONAGH, Josephine. Space, Mobility, and the Novel: "The spirit of place is a great reality". In. BEAUMONT, Mathew (org.). Adventures in Realism. Oxford: Blackwell Publishing, 2007.

MIRANDA, Gabriel Fernandes de. Imagens do Meio Rural Inglês em "The Rings of Saturn" e "The Enigma of Arrival". In. Congresso da Associação Brasileira de Literatura Comparada, XV, v. 2, 2017, Rio de Janeiro. Anais. p. 2608-2619. Disponível em: < $\underline{\text { http://abralic.org.br/ }}$ downloads/2017_anais_ABRALIC_vol_2.pdf $>$

NAIPAUL, V.S. The Enigma of Arrival. London: Picador, 2011 [1987].

NIXON, Rob. London Calling: V.S. Naipaul, Postcolonial Mandarin. New York: Routledge, 1992.

OLIVEIRA, Manoela Hoffmann. Crítica ao conceito Bildungsroman. Revista Investigações, janeiro/2013, v. 26, n. 1, p. 1-39.

RONEN, Ruth. Space in Fiction. Poetics Today., Durham, 1986, v. 7, n. 3, p. 421-438,

RUSHDIE, Salman. Imaginary Homelands. London: Granta Books, 1991.

SELBMANN, Rolf. Einleitung In. SELBMANN, Rolf (Org.). Zur Geschichte des deutschen Bildungsroman. Darmstadt: Wissenschaftliche Buchgesellschaft, 1988, p. 1-44.

WILLIAMS, Raymond. The Country and The City. New York: Oxford University Press, 1975. 


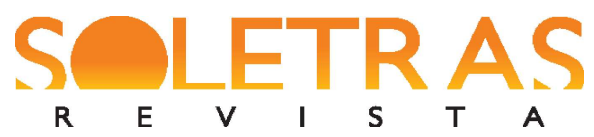

N. $38-2019.2$ - GABRIEL FERNANDES DE MIRANDA

\title{
Space and displacement in The Enigma of Arrival and Youth
}

\begin{abstract}
The present article intends to analyze the special constructions in two contemporary novels in the English language by V.S Naipaul and J.M Coetzee from a historical perspective, meaning to comprehend the forms of dialogue with the traditional figuration of narrated spaces. The article also looks to the developing of logics of belonging for the autofictional protagonists of the novels, with the centrality of the concept of displacement and the procedures of special figuration which, gradually, define sceneries that don't welcome the protagonists. The article was based on multiple theoretical references with special attention to the contributions of the cultural studies to the comprehension of the place of literature on the expanded field of discourses that circulate in the social web. The analysis ends with the conclusion that both novels present radical displacements for their protagonists from the negative figuration of the spaces in question, be it that from England, or the place of origin, producing a kind of suspension that points to the impossibility of conventional forms of belonging for the characters.
\end{abstract}

Keywords: Displacement. Space. Belonging.

Recebido em: 14 de junho de 2019.

Aceito em: 22 de agosto de 2019. 